\title{
Comment on Suzuki et al.: "Fluctuation of serum C3 levels reflects disease activity and metabolic background in patients with IgA nephropathy"
}

\author{
Onur Sakallığlu
}

Received: 29 September 2013/Accepted: 22 April 2014/Published online: 6 June 2014

(C) Italian Society of Nephrology 2014

Dear Editor,

I read with great interest the study by Suzuki et al. [1], in which the authors conclude that fluctuations in C3 levels may be monitored to estimate disease activity along with hematuria, proteinuria and renal function in immunoglobulin (Ig)A nephropathy. However, some equivocal results lead us to discuss the conclusions of the study.

Firstly, the fluctuated mean \pm SD values in the group with the deterioration are so similar to the groups with amelioration that we consider the difference was to a large extent owing to the number of patients in the groups. In fact, the authors suggested such a possibility in the discussion section regarding the corticosteroid-administered group. Additionally, the suspicious results in Group II and Group III are contrary to the main theme of the study. Instead of basing their explanation of Group III on a previous report about obesity and age, I suggest to compare fluctuations of $\mathrm{C} 3$ in their older IgA nephropathy patients with obesity. As a matter of fact, body weight and body mass index are not significantly different from other groups in Group III at Table II. Triglyceride and total cholesterol levels need to be confirmed for groups II-III and fasting plasma glucose for groups I-III. So, it is difficult to consider a reliable link between C3 levels and disease activity or metabolic background.

Secondly, the authors say that $\mathrm{C} 3$ is consumed in $\operatorname{IgA}$ nephropathy despite being in the cutoff range. I wonder about the explanation of $\mathrm{C} 4$ and $\mathrm{CH} 50$ decrement, despite their being in the cutoff range in the study.

Thirdly, there are some technical problems related to standardization of the quantification of complement levels. The standardization and the quality control of the assay is to a large extent missing [2]. I suggest confirming the results of the study either with different measurement methods or commercial kits.

Conflict of interest None disclosed.

\section{References}

1. Suzuki H, Ohsawa I, Kodama F et al (2013) Fluctuation of serum C3 levels reflects disease activity and metabolic background in patients with IgA nephropathy. J Nephrol 26(4):708-715

2. Mollnes TE, Jokiranta TS, Truedsson L et al (2007) Complement analysis in 21st century. Mol Immunol 44:3838-3849

A reply to this comment can be found at doi:10.1007/s40620-0140088-6.

\section{O. Sakallıoğlu}

Department of Pediatric Nephrology, Baskent University Faculty of Medicine, Zübeyde Hanım Practicing and Training Hospital, Karşıyaka, Izmir, Turkey

O. Sakallığlu $(\square)$

Cumhuriyet Bulvarı No:333/2, Alsancak, Izmir, Turkey

e-mail: onursakallioglu@hotmail.com 